\title{
Methodological Proposal for the Development of Insurance Policies for Building Components
}

\author{
Miguel Macedo ${ }^{1}$, Jorge de Brito ${ }^{1,2}\left(\mathbb{D}\right.$, Carlos Oliveira Cruz ${ }^{1,2} \mathbb{C}$ and Ana Silva ${ }^{1,2, *}$ \\ 1 Department of Civil Engineering, Architecture and Georresources, Instituto Superior Técnico, \\ Universidade de Lisboa, Av. Rovisco Pais, 1049-001 Lisbon, Portugal; miguel.macedo@ist.utl.pt (M.M.); \\ jb@civil.ist.utl.pt (J.d.B.); oliveira.cruz@tecnico.ulisboa.pt (C.O.C.) \\ 2 CERIS-Civil Engineering Research and Innovation for Sustainability, Department of Civil Engineering, \\ Architecture and Georresources, Instituto Superior Técnico, Universidade de Lisboa, Av. Rovisco Pais, \\ 1049-001 Lisbon, Portugal \\ * Correspondence: ana.ferreira.silva@tecnico.ulisboa.pt
}

Received: 17 March 2020; Accepted: 16 May 2020; Published: 19 May 2020

\begin{abstract}
Insurance is a growing economic activity within the construction sector. Homes and buildings are perhaps the most important investment an individual makes in his/her lifetime. Nevertheless, the market for insurance coverage policies applied to the building envelope is in an embryonic stage, mainly due to the lack of knowledge in terms of risk and costs associated to the failure of these elements. This study provides an innovative and methodological approach to the development of an insurance product that targets the obsolescence of building components. In defining a structured approach to the design of insurance policies for buildings, the use of the service life prediction models proposed in this study allows establishing different types of insurance policies with different risk premiums and evaluating different losses and risks accepted by the owners, thus promoting the increase of the patrimonial value of the asset and reducing the risk of premature failure and the uncertainty of the costs of maintenance during its life cycle.
\end{abstract}

Keywords: insurance policies; obsolescence of building components; service life prediction; risk premiums

\section{Introduction}

The use of insurance to manage construction risks has been a common practice of the construction sector to mitigate the risk of the premature damage of building components from exposure to climate loads $[1,2]$. The construction sector is particularly vulnerable to such risks given the nature of the activity, which is characterized by a significant vulnerability of long-term assets to external factors (environmental, social, political, or economic), with a direct impact on buildings' service life as well as on their performance levels [3]. There are a set of drivers of change that will have a profound impact on the way insurance products are designed, commercialized and managed [4], which are shown as following: (i) climate change and the associated challenges putting pressure on the traditional risk analysis, given the increasing frequency of natural catastrophes and extreme weather events [5]; (ii) the growing urbanization of vulnerable areas, from a seismic and climatic perspective, such as Iran or Mexico, which increases the number of buildings at risk [6]; (iii) the growing trend in the outsourcing of building maintenance [7]. Owners and investors outsource the responsibility for the daily maintenance of buildings to third parties (i.e., companies specialized in building's maintenance, usually spin-offs of traditional construction companies). Although these maintenance contracts can include some corrective maintenance, their focus is preventive maintenance actions [8]. The choice of this model for the maintenance allows owners to pass on this responsibility to specialized third parties, which may decrease the overall life cycle costs, but frequently limit the level of risk assumed. 


\section{Description of the Problem}

Insurance policies have been evolving towards providing a protection to owners, investors, and users of buildings; nonetheless, the object of the insurance is, in most cases, to protect the building as an indivisible unit [9]. This means that most construction insurance policies provide a coverage that does not allow differentiating the several different components that comprise a building such as roofs, façades, claddings, and fenestration. These several components have entirely different technical characteristics, employ different materials and involve distinct construction processes as well as entirely distinct maintenance and replacement costs. Ultimately, the components necessarily have distinct service lives, which may vary from seven to 30 years or more. The starting point for this research is the possibility of consideration for several durability layers, having different rates of degradation over time, thus breaking down the buildings components and developing specific insurance coverage products for these components: This would allow for a more incremental but comprehensive approach to providing building insurance coverage to building owners. Naturally, when the objective is to have a comprehensive coverage against, for example, extreme weather events, the most appropriate solution will always be a building's entire insurance coverage. However, there is likely a potential market for specific insurance coverage for buildings components, particularly considering the fact that some maintenance contracts exclude several components of the building or, at least, limit the responsibility of the maintenance company. The concept is to provide an insurance against expected malfunctions, without consideration of damage arising from external extreme events (i.e., seismic- or climate-related).

The most significant barrier to the development of such insurance products is the relatively unknown long-term behavior of materials and components. Without a reasonable level of knowledge regarding lifespans and particularly the degradation curves (or loss of performance over time), insurance companies would not accept the tolerance of such levels of risk.

The application of durability models to the insurance sector is still in a nascent phase. This study intends to fill that gap, proposing an innovative conceptual methodological model for the development of building component insurance products. In this methodology, the definition of an insurance policy is made on the basis of both deterministic and stochastic models, which are founded on the progressive degradation of the building element under analysis over time and according to its physical characteristics. It is supposed that the application of the proposed service life prediction models would allow obtaining more realistic insurance policies, given the fact that the risk of failure of the building components and the related costs would be evaluated in a more accurate manner. This proposed methodology thus increases the insurer's capability of estimating expected claims and thus the risk load taken on by the insurer, according to the building component under analysis, following a probability approach [10,11].

\section{State of the Art}

In very simplistic terms, existing insurance policies for buildings can be organized in two broad types: those that are designed for home owners and investors and are used to ensure protection against extreme events and those intended for building owners, providing coverage against construction defects and anomalies and usually working as an extension of the typical construction guarantee, which is usually five years after construction but may vary from country to country. Quite frequently, the coverage provided by both types is offered within the same insurance policy. Table 1 presents a summary of several construction insurance coverage policies, focusing only on the more advanced types, which include protection against construction defects. 
Table 1. Summary of typical construction insurance coverage.

\begin{tabular}{|c|c|c|c|c|}
\hline Insurance Company & Insurance Type & Duration & Type of Building & Coverage \\
\hline $\begin{array}{l}\text { Evolution } \\
\text { Insurance Group }\end{array}$ & $\begin{array}{c}\text { Building } \\
\text { Warranties \& } \\
\text { Latent Defects } \\
\text { Insurance }\end{array}$ & 10 years & $\begin{array}{l}\text { Residential and } \\
\text { commercial }\end{array}$ & $\begin{array}{l}\text { Partial or full reconstruction against } \\
\text { construction defects or structural anomalies } \\
\text { Repair of roofs, façades and windows }\end{array}$ \\
\hline \multirow{2}{*}{ BLP Insurance } & BLPSECURE & 10 or 12 years & All types & $\begin{array}{l}\text { Partial or full reconstruction against } \\
\text { construction defects or structural anomalies }\end{array}$ \\
\hline & BLPASSET & 6,10 or 12 years & All types & $\begin{array}{l}\text { Partial or full reconstruction against } \\
\text { construction defects }\end{array}$ \\
\hline $\begin{array}{c}\text { Local Authority } \\
\text { Building Control } \\
\text { (LABC) }+\mathrm{MD} \\
\text { Insurance Services Ltd }\end{array}$ & $\begin{array}{l}\text { LABC New Home } \\
\text { Warranty }\end{array}$ & $\begin{array}{c}5 \text { years after } \\
\text { construction }+10 \text { years } \\
=\text { total coverage of } \\
15 \text { years }\end{array}$ & $\begin{array}{l}\text { Social housing, } \\
\text { Residentia, }\end{array}$ & $\begin{array}{l}\text { Protection against insolvency of the contractor } \\
\text { Protection against construction defects. }\end{array}$ \\
\hline
\end{tabular}

\section{Materials and Methods}

\subsection{Context}

The subscription process is preceded by the design of the insurance policy, which is the central issue here. The design of an insurance product is essentially an exercise of predicting the probability of a given event. Associated with it is the corresponding need to assess the incurred costs, but this is generally a far simpler calculation than the probability of occurrence. Having in mind insurance policies for building components, the most critical stage is the understanding, definition, and calculation of degradation models. These represent the evolution of degradation throughout time, and an essential element is to identify the expected condition of the building element in each instant and at the end of its service life. In this study, the process of design of an insurance coverage policy in divided into six stages, as summarized in Figure 1.

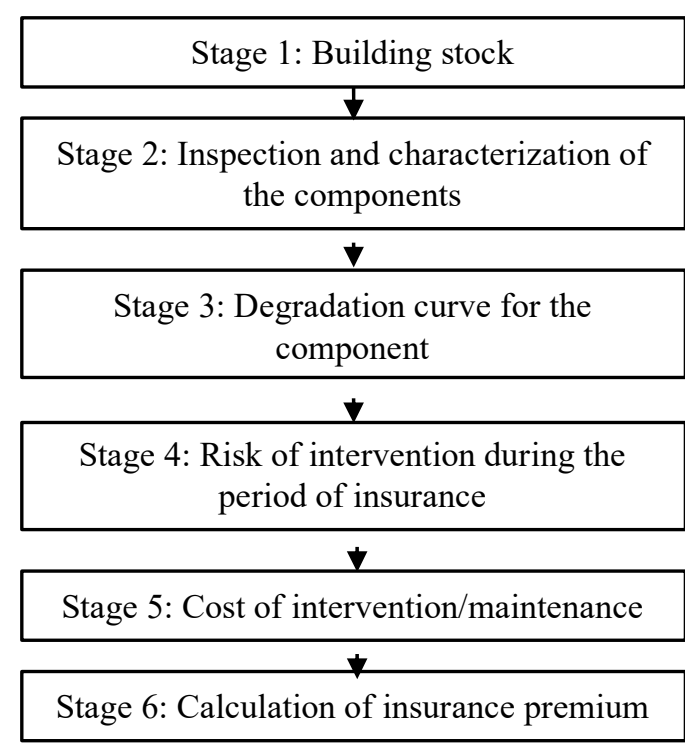

Figure 1. Scheme of the methodological approach to determining adequate construction insurance coverage.

Stages 1 and 2 involve identifying and quantifying the potential numbers of subscribers and buildings to be insured (stage 1) and characterizing the main components (stage 2).

Stages 3 to 5 are intended for identifying, for the insurance company, the potential cost associated with the product. Stage 3 is particularly complex and probably constitutes the most critical aspect of the process. Clearly, given its current low level of development, it represents the most important 
bottleneck to a broad adoption of this type of products. It involves determining the degradation curve for each component, i.e., how the expected level of service evolves over time. Based on this curve, it is possible to determine the risk of the need of a given intervention (stage 4) to re-establish a proper level of performance of the element. This intervention has an estimated associated cost, usually determined based on market costs (stage 5). Stage 6 involves calculating the insurance premium, based on the expected costs calculated in stage 5 . This methodological approach should be applied to each building component, for which an insurance coverage policy is designed.

\subsection{Types of Models Proposed for Service Life Prediction}

The insurance methodology exploits four increasingly complex types of service life prediction models: single-parameter deterministic, multiparameter deterministic, single-parameter stochastic, and multi-parameter stochastic models. The proposed models are based on a numerical index, called severity of degradation $\left(S_{w}\right)$, used to quantify the physical and visual degradation observed in a given building component. This index [12] encompasses the extent, condition, and cost of repair of various potential defects in the building component under analysis, as shown in Equation (1):

$$
S_{w}=\frac{\sum\left(A_{n} \times K_{n} \times k_{a, n}\right)}{A \times K}
$$

where $S_{w}$ represents the severity of degradation of the building component, expressed as a percentage, $k_{n}$ is the multiplying factor of defect " $n$ " as a function of their degradation level with range $K=\{0,1,2$, $3,4\}, k_{a, n}$ is the weighting factor corresponding to the relative weight of the anomaly detected $\left(k_{a, n} \in \mathrm{R}+\right.$. When no instructions are provided, it is assumed that $k_{a, n}=1$.), $A_{n}$ is the area of the element affected by a defect " $n$ " in $\mathrm{m}^{2}, A$ is the façade area in $\mathrm{m}^{2}$ and $k$ is the multiplying factor corresponding to the highest degradation level of an element of area $A$. In this general framework model, five degradation conditions are considered from level A-a building component without visible degradation (the most favourable condition) to level $\mathrm{E}$ - a building component with generalized degradation (the most serious degradation level).

The single-parameter deterministic model corresponds to the definition of a degradation curve, illustrated graphically as the loss of performance of a building component over time. This curve correlates the severity of degradation of the building component (based on visual inspections carried out on site) and a given age (a single parameter used to explain the variability of the degradation condition of the element). The degradation curves of different components can present different patterns, according to the deterioration mechanisms and agents they are subjected to throughout their service life [13]. In the description of the degradation of external claddings, an "s-shaped" curve is usually adopted [14] (Figure 2), which changes its intensity over time. Initially, the building component tends to show premature defects, with a more rapid deterioration pace; afterwards, the path tends to apparently stabilize over time, and the cumulative effects of the deterioration agents are felt near the end of the component's service life, thus promoting the acceleration of the deterioration process.

The single-parameter deterministic model provides a degradation curve for the entire sample analyzed and an average estimated service life, regardless of its characteristics. This approach gives an estimate of the component's service life with a known confidence level but could be too restrictive given the complexity of the degradation phenomenon. In this sense, it is relevant to propose multidimensional deterministic models, from which the degradation of the building components can be analyzed. Silva et al. $(2016 \mathrm{a} ; \mathrm{b})[14,15]$ proposed several models for the description of the severity of degradation using multiple regression analysis, e.g., multiple linear regression models and polynomial and sigmoidal models. 


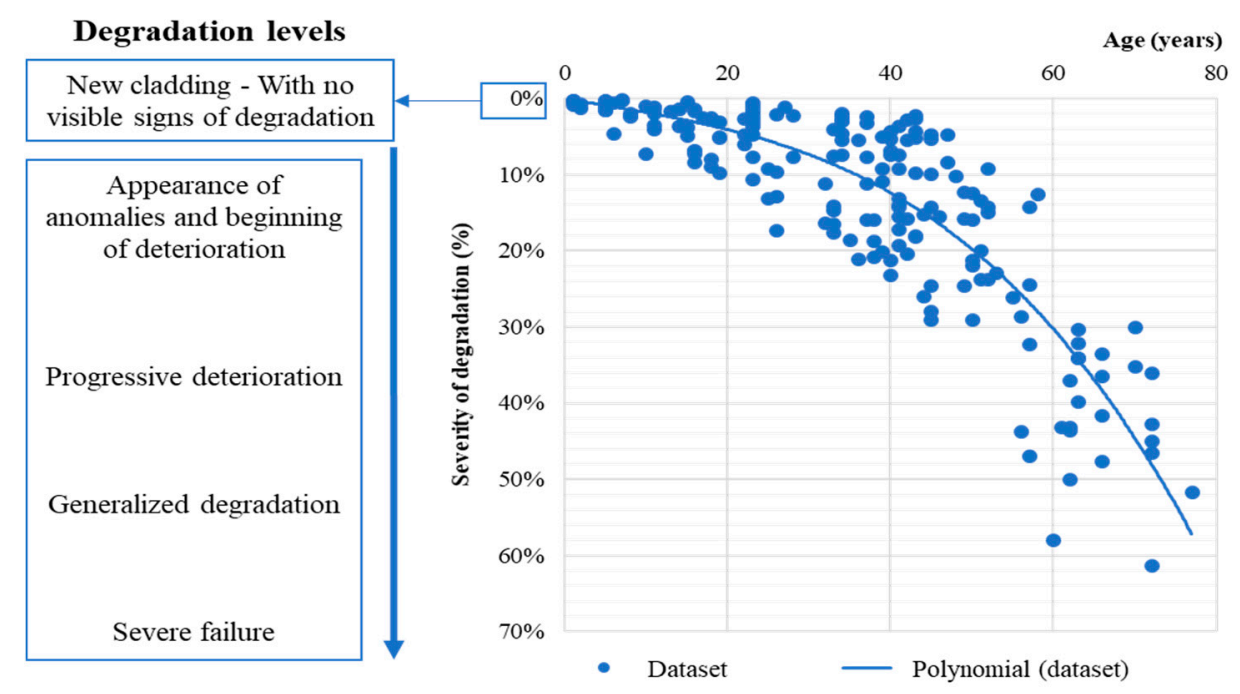

Figure 2. Illustrative example of a degradation curve for external claddings.

These models may include an arbitrarily large number of explanatory variables, related with the degradation of a given element, always considering the physical sense and empirical knowledge of how some variables affect the degradation of the component. These multiparameter models allow obtaining an estimated service life for a given component, according to its age and characteristics, thus providing a more accurate estimation regarding the instant when it is necessary to intervene.

Deterministic models provide an absolute value (with a series of dispersion measures) of the estimated service life of building components but do not allow evaluating the risk of failure of the building elements over time. In reality, buildings have associated probabilities of reaching the end of service life, which increase with age. The objective of an insurance company is to transform those probabilities into costs, which is able to include unexpected situations during the buildings' service life, regardless of the origin of the unforeseen events.

Stochastic models are thus extremely useful in the context of insurance policies [16], since these models are able to represent building degradation as a stochastic process [17]. Single-parameter stochastic models allow estimating the probability of failure of a given component at a given age. Multiparameter stochastic models allow for a more comprehensive analysis and the encompassment of relevant variables to an explanation for the degradation of the building component, thus providing a probability distribution function, then allows estimating the probability of the element reaching the end of its service life according to their characteristics. With this information, one can define, for different risk thresholds, the probability of a given element reaching the end of its service life. These models allow reducing the risk assumed by the insurance company, by evaluating whether the planned maintenance activities must be anticipated or delayed, according to the degradation threshold and the risk of the element exhausting its service life.

\subsection{Model Parameters}

Knowing the degradation condition state and service life of the building component, one can establish the coverage of the proposed insurance policy and the contractual guarantees. A claim-filing process could, for example, occur in three $S_{w}$ thresholds and include a specific maintenance action: cleaning $(C)$ is performed, before $S_{w}$ reaches $x \%$; major intervention $(M I)$ is performed, before $S_{w}$ reaches $y \%$; replacement $(R)$, before $S_{w}$ reaches $z \%$. The condition levels $x, y$, and $z$ must be defined according to the stakeholders' level of demand, influenced by the buildings' economic and social context, legal requirements, and even the funds available for maintenance actions. Naturally, more demanding stakeholders and contexts will adopt stricter levels sooner by performing the maintenance actions for lower levels of $S_{w}$ than stakeholders that accept higher degradation levels. During the periodic 
assessments, the insurance company registers the $S_{w}$ value in a detailed report. Based on this, the insurance entity decides whether to approve the repair budget.

The maintenance services present some limitations: (i) for each policy (building component), each of the described actions is made only once. After a cleaning action, the insurer will not intervene until the next maintenance action; (ii) it is simplistically considered that the maintenance actions have no effect on the value of $S_{w}$. The component's estimated service life is the same before and after the intervention; (iii) it is assumed that the insurer performs no periodic building maintenance; (iv) for multi-flat buildings, the insurance is equally shared, and each owner pays the same premium.

An annual policy with a renewal option is proposed. When the client accepts to pay for this protection, the premium is fixed as long as the subscription continues, independently from the volatility of the rate. This is beneficial for the insurer, as he/she knows how much to pay each year without surprises, hassles, or additional calculations.

\subsection{Calculation of the Insurance Premium}

The difference between the expected service life and the building component's age results in different time periods, $t . t_{C}, t_{M I}$, and $t_{R}$ are the periods to perform the cleaning $(C)$, major interventions $(M I)$, and replacement $(R)$, respectively. In these periods, money has different present values. The insurance entity expects a replacement cost (negative cash flow) of $C_{t}$ Euros at the end of year $t$ with a discount rate $r$ [18]. The present value of this future payment is calculated by Equation (2):

$$
P V=\frac{C_{t}}{(1+r)^{t}}
$$

The advantage of the present values is that they are all expressed in current Euros, so one can add them up. For the designed insurance product, the total present value is given by Equation (3):

$$
P V=\frac{C_{t, n o m(C)}}{\left(1+r_{\text {nom }}\right)^{t_{C}}}+\frac{C_{t, \text { nom }(M I)}}{\left(1+r_{\text {nom }}\right)^{t_{M I}}}+\frac{C_{t, \text { nom }(R)}}{\left(1+r_{\text {nom }}\right)^{t_{R}}} .
$$

The terms $C_{t, n o m(C)}, C_{t, n o m(M I)}$, and $C_{t, n o m(R)}$ correspond to the nominal costs of the maintenance actions of the different degradation thresholds $\left(t_{C}, t_{M I}\right.$, and $t_{R}$, respectively), indicating the years, in which those costs occur, and $r_{\text {nom }}$ represents the nominal discount rate, which includes the global inflation risk, opportunity costs, and other costs. In Equation (3), the terms $C_{t, \operatorname{nom}(C)}, C_{t, \operatorname{nom}(M I)}$, and $C_{t, n o m(R)}$ account for the effect of inflation. The way inflation affects the nominal discount rate is explained by Fisher's theory [18], as in Equation (4):

$$
1+r_{\text {nominal }}=\left(1+r_{\text {real }}\right) *(1+i) \Leftrightarrow r_{\text {real }}=\frac{1+r_{\text {nominal }}}{1+i}-1
$$

It is critical to be consistent utilizing nominal or real values when working with cash flows and discount rates. If, for example, the value of $r_{\text {nominal }}$ is $6 \%$, cash flows must be converted to nominal terms and discounted at $6 \%$. To work in nominal terms, one must consider trends in equipment, labour, and material costs. Therefore, both a construction inflation rate $\left(i_{s}\right)$ and a global inflation rate $\left(i_{g}\right)$ should be adopted. To simplify the presentation of results, real values are used. The present value of the costs is presented as Equation (5):

$$
P V, \text { cost }=\frac{C_{t, \text { real }(C)}}{\left(1+r_{\text {real }, \text { cost }}\right)^{t_{C}}}+\frac{C_{t, \text { real }(M I)}}{\left(1+r_{\text {real }, \text { cost }}\right)^{t_{M I}}}+\frac{C_{t, \text { real }(R)}}{\left(1+r_{\text {real }, \text { cost }}\right)^{t_{R}}},
$$

where $C_{t, \text { real }(C)}, C_{t, \text { real }(M I)}$, and $C_{t, \text { real }(R)}$ are the real costs of the maintenance actions of the different degradation thresholds, equal for all proposed models; $t_{C}, t_{M I}$, and $t_{R}$ are the respective years, in which these costs occur; $r_{\text {real,cost }}$ is the real discount rate, the same for all the models and obtained by 
Equation (4). The discount rate applied to the cost is presented in Equation (6), which solely accounts for the inflation rate $i_{s}$ :

$$
r_{\text {real }, \text { cost }}=\frac{1+r_{\text {nominal }}}{1+i_{s}}-1
$$

Equation (7) allows estimating the present value of the premium.

$$
P V, \text { premium }=\frac{C_{t, \text { premium }}}{\left(1+r_{\text {real, premium }}\right)^{1}}+\frac{C_{t, \text { premium }}}{\left(1+r_{\text {real,premium }}\right)^{2}}+\ldots+\frac{C_{t, \text { premium }}}{\left(1+r_{\text {real,premium }}\right)^{t_{40}}}
$$

where $C_{t, \text { premium }}$ is the annual premium in $€ / \mathrm{m}^{2}$, which is the main result obtained from these models. The value of $r_{\text {real,premium }}$ represents a real discount rate equal for all the models. This value takes into consideration not only the rate $i_{s}$ but also the rate $i_{g}$, as seen in Equation (8):

$$
r_{\text {real,premium }}=\frac{1+r_{\text {nominal }}}{\left(1+i_{s}\right) *\left(1+i_{g}\right)}-1
$$

Equaling Equations (5) and (7), the premium value $\left(C_{t, \text { premium }}\right)$ is obtained and converted to Euros paid per household (building) by multiplying the premium by the area of the building element and dividing this number by the number of flats. At this stage, the model does not consider the insurance company's profit margin. Based on the results of each model, one can translate each probability into a profit margin.

\section{Results, Discussion, and Limitations of the Proposed Models}

The development of insurance policies for building components offers the construction sector and particularly home owners and investors the potential to pass on to third parties the risk associated with the performance of specific building components. This represents a more detailed and incremental layer than that presently available to the insurance market, which typically considers the building as an entire insurance unit. Nevertheless, such a type of insurance products has some limitations: (i) it needs a significant amount of data to be able to calculate in detail the degradation curves of each component; (ii) given the specificities of each country and the respective construction practices, these curves are required to be developed for each specific geographic location; (iii) it involves performance inspections, which can increase transaction costs when establishing the insurance coverage to a level that can jeopardize the economic viability of the product. The application of this model would be more advantageous for groups of buildings (under management by the same entity). This allows obtaining economies of scale and mitigating higher transaction costs associated with the product. Such effects are not considered, so the minimum number of insurances for ensuring a break-even analysis is not determined. Future developments of the model should account for such effects.

\section{Conclusions}

This study is intended as a refinement for insurance coverage policies for the construction sector, particularly regarding the protection of buildings from aging and material deterioration, as occurs in most industrial sectors around the globe. A greater knowledge on the behavior of materials will certainly play a crucial role in this development. However, the nature and type of models are still at an early stage of development. Unlike single-parameter models, the characteristics of segmentation in multi-parameter models may allow reducing insurance premiums through increased knowledge of the insured objects. Moreover, stochastic models allow quantifying the risk of failure of buildings components as well as that associated with decisions related with the required maintenance actions during a building element's service life. The increase in a model's sophistication can lead to a decrease in the clients' premium and an increase in the company's safety, creating a beneficial situation for both parties. This is an area that will need to be further developed through the use of specific cases studies 
to allow obtaining more detailed information and drawing more substantive conclusions. Over the long term, such types of measures can affect the profits per client, but a greater number of clients and a global decrease in risk are expected with improvement of service and a lower premium. This product has several advantages:

- In residential condominiums, the insurance can be issued by sharing risks within the households and resulting in a reduced premium for each household; it promotes more durable and sustainable building construction with higher quality and performance levels, since the insurance discourages inadequate options in materials and construction practices;

- Insurance companies schedule and perform the "examination", when the claim is made, unlike what happens in most of housing. As they have no interest in delaying building maintenance, the insured units gain a renewed look, benefitting the image of the neighborhood and city at large;

- The insurance product developed in this fashion can be summarized as a service given to the clients, so its usefulness raises the global value of the building having coverage. This allows commercializing the insurance by real estate promotion, apart from the usual distribution channels (e.g., internet, banks, brokers, and agents).

- This product can also be especially interesting to specialized maintenance companies, since it allows for an additional degree of protection against the risk of early degradation of materials.

Author Contributions: Conceptualization, J.d.B. and C.O.C.; methodology, J.d.B., C.O.C., and A.S.; formal analysis, M.M.; investigation, M.M.; writing of the original draft preparation, A.S. and C.O.C.; writing of review and editing, A.S. and J.d.B. All authors have read and agreed to the published version of the manuscript.

Funding: This research was funded by the Foundation for Science and Technology (FCT) through project PTDC/ECM-COM/5772/2014.

Acknowledgments: The authors gratefully acknowledge the administrative and technical support of the CERIS Research Institute, IST, the University of Lisbon, and the FCT.

Conflicts of Interest: The authors declare no conflicts of interest.

\section{References}

1. Akintoye, A.S.; MacLeod, M.J. Risk analysis and management in construction. Int. J. Proj. Manag. 1997, 15, 31-38. [CrossRef]

2. El-Adaway, I.H.; Kandil, A.A. Construction risks: Single versus portfolio insurance. J. Manag. Eng. 2010, 26, 2-8. [CrossRef]

3. Yang, R.J.; Zou, P.X.W. Stakeholder-associated risks and their interactions in complex green building projects: A social network model. Build. Environ. 2014, 73, 208-222. [CrossRef]

4. Bunni, N.G. Risk and Insurance in Construction, 2nd ed.; Routledge: Abingdon, UK, 2003.

5. Kunreuther, H. Reducing losses from catastrophes: Role of insurance and other policy tools. Environment 2016, 58, 30-37. [CrossRef]

6. Brechin, S.R.; Espinoza, M.I. A case for further refinement of the green climate fund's 50:50 ratio climate change mitigation and adaptation allocation framework: Toward a more targeted approach. Clim. Chang. 2017, 142, 311-320. [CrossRef]

7. Suweero, K.; Moungnoi, W.; Charoenngam, C. Outsourcing decision factors of building operation and maintenance services in the commercial sector. Prop. Manag. 2017. [CrossRef]

8. Shohet, I.M.; Nobili, L. Application of key performance indicators for maintenance management of clinics facilities. Int. J. Strateg. Prop. Manag. 2017, 21, 58-71. [CrossRef]

9. Blong, R. Residential building damage and natural perils: Australian examples and issues. Build. Res. Inf. 2004, 32, 379-390. [CrossRef]

10. Flage, R.; Aven, T.; Zio, E.; Baraldi, P. Concerns, Challenges, and Directions of Development for the Issue of Representing Uncertainty in Risk Assessment. Risk Anal. 2014, 34, 1196-1207. [CrossRef] [PubMed]

11. Colyvan, M. Is probability the only coherent approach to uncertainty? Risk Anal. 2008, 28, 645-652. [CrossRef] [PubMed] 
12. Gaspar, P.L.; de Brito, J. Limit States and Service Life of Cement Renders on Façades. J. Mater. Civ. Eng. 2011, 23, 1396-1404. [CrossRef]

13. Shohet, I.M.; Puterman, M.; Gilboa, E. Deterioration patterns of building cladding components for maintenance management. Constr. Manag. Econ. 2002, 20, 305-314. [CrossRef]

14. Silva, A.; de Brito, J.; Gaspar, P.L. Methodologies for Service Life Prediction of Buildings; Springer International Publishing AG: Basel, Switzerland, 2016.

15. Silva, A.; de Brito, J.; Gaspar, P.L. Comparative analysis of service life prediction methods applied to rendered façades. Mater. Struct. Constr. 2016, 49, 4893-4910. [CrossRef]

16. Ranasinghe, M. Risk management in the insurance industry: Insights for the engineering construction industry. Constr. Manag. Econ. 1998, 16, 31-39. [CrossRef]

17. Madrigal, L.O.; Bretones, J.M.F.; Lanzarote, B.S. Proposed method of estimating the service life of building envelopes. Rev. Constr. 2015, 14, 60-68.

18. Stapleton, R.C.; Brealey, R.; Myers, S. Principles of Corporate Finance; Tata McGraw-Hill Education: New York, NY, USA, 2006.

(C) 2020 by the authors. Licensee MDPI, Basel, Switzerland. This article is an open access article distributed under the terms and conditions of the Creative Commons Attribution (CC BY) license (http://creativecommons.org/licenses/by/4.0/). 